\title{
Best vitelliform macular dystrophy
}

INSERM

\section{Source}

INSERM. (1999). Orphanet: an online rare disease and orphan drug data base. Best vitelliform macular dystrophy. ORPHA:1243

Best vitelliform macular dystrophy (BVMD) is a genetic macular dystrophy characterized by loss of central visual acuity, metamorphopsia and a decrease in the Arden ratio secondary to an egg yolk-like lesion located in the foveal or parafoveal region. 